\title{
Influencing of land transport load on structure of backfill arched Road Bridge
}

\author{
Mirzakhid Miralimov ${ }^{*}$, Abdurakhman Ishankhodjaev, Khudaybergan Almenov, and Eldior \\ Muminov \\ Tashkent State Transport University, Tashkent, Uzbekistan
}

\begin{abstract}
In this paper, for the objective assessment of stress-strain state parameters of backfill arched road bridge, the research work is carried out, where the model of reinforced concrete, corrugated structure is exposed to modern land transport load.

In the course of numerical studies, stresses and deformations in sections of structure and the soil are determined. These studies allow revealing the mechanism of operation of corrugated reinforced concrete structures in the body of an embankment of highways when passing modern transport loads along with them.
\end{abstract}

\section{Introduction}

In road construction for the intersection of small and medium-sized watercourses, singlepoint, multi-point pipes or small-span beam bridges are mainly designed and erected [1]. The construction of girder bridges to overlap the bridge hole requires increasing the size of the superstructure.

Besides, in girder bridges, movable live load acts directly on the superstructure, which is one of the reasons for the structural wear. The situation is getting worse by the introduction of increased loads from the vehicles like A14, NK-100 [2]. To a certain extent, the solution to this problem is the construction of backfill structures, i.e. structures of which are part of road embankment.

\footnotetext{
*Corresponding author: miralimov_mm@yahoo.com
} 

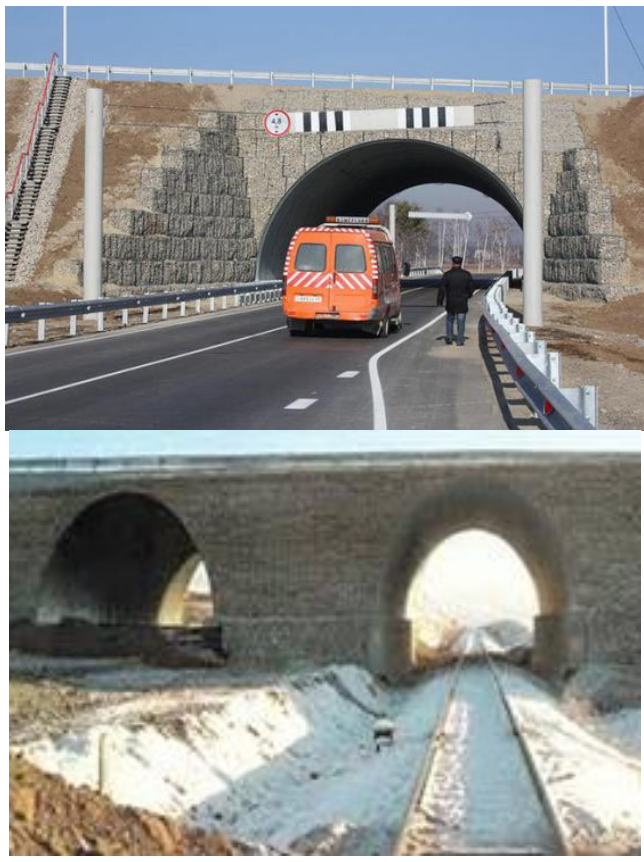

Fig.1. Examples of backfill small arched bridges

A promising direction, in this case, is low-span arched backfill bridges which allow replacing culverts and low-span beam bridges, which have a combination of the advantages of these structures and eliminate their disadvantages (fig. 1). Their advantage is the economic efficiency of construction [3].

The use of backfill arched bridges made of reinforced concrete vaulted elements can be placed with any combination of the plan and profile of road (on curves in the plan, in the presence of vertical curves, both convex and concave, etc.) and ensures uniform distribution of temporary loads from vehicles in the body of embankment roads, which significantly reduces dynamic impacts [4].

Lightweight prefabricated structures allow using light lifting capacity cranes without using special lifting and transport equipment (fig. 2). Giving to a cross-section of arches corrugated (triangular, trapezoidal) or wavy outline can be increased the bearing capacity of bridges and the length of their span [5].

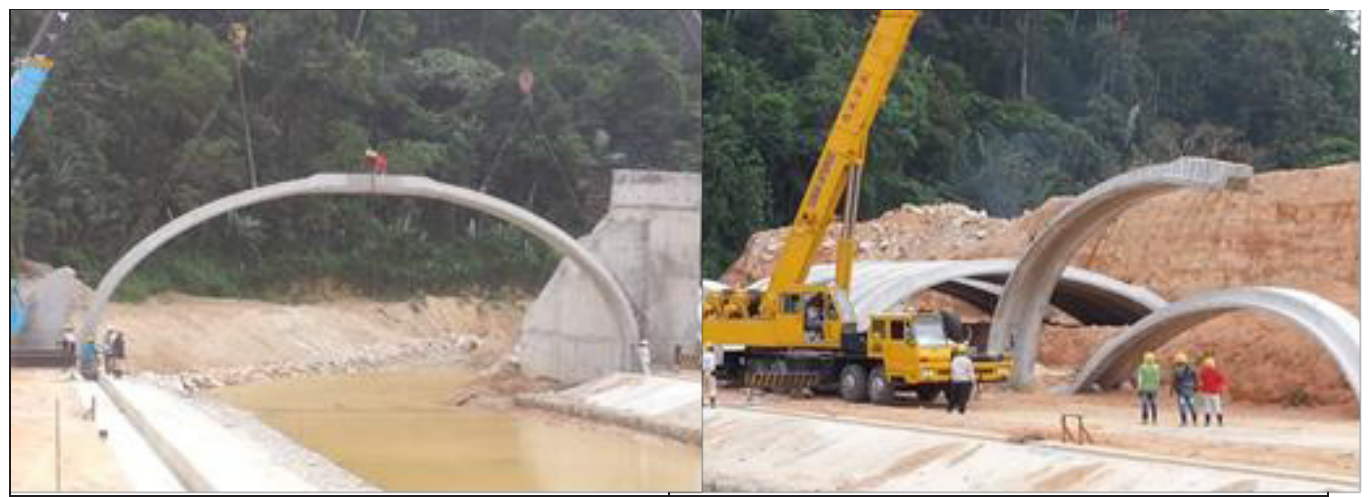

Fig. 2. Construction of backfill arched Road Bridge 
To check the operational reliability of prefabricated structures, it should be examined for its bearing capacity when exposed to temporary land transport loads (Figure 3).
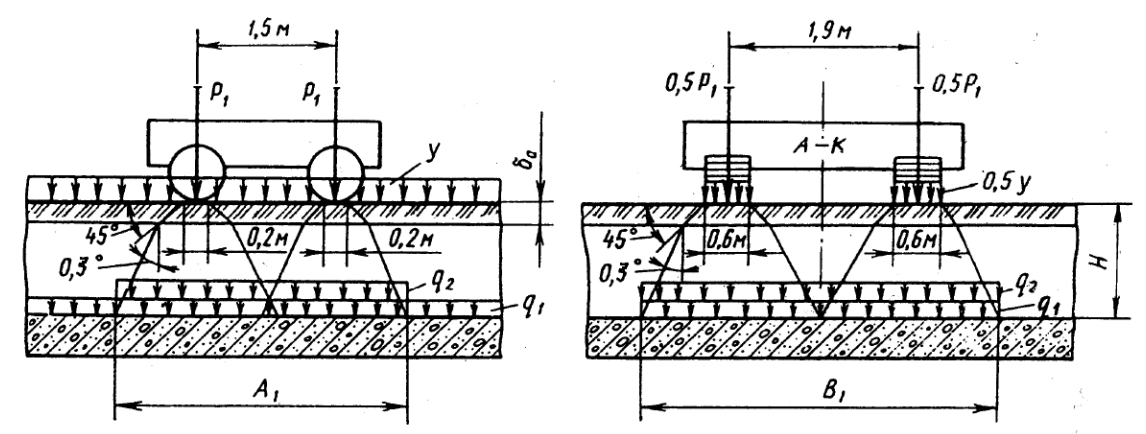

Fig. 3. The scheme for determining of vertical pressure from vehicles in the form of AK land transport loads

\section{Methods}

The arched structure working in conjunction with the surrounding soil environment is a complex, repeatedly static, indeterminate structure. Under the action of active external loads, the structure deforms, changing its position.

A possible option for calculating the "arch-soil" system using the finite element method is the computation plane scheme. The arched structure is represented as a curved bar of arbitrary outline with geometric and strength characteristics for the width of $1.0 \mathrm{~m}$. Let's consider a body defined two-dimensional area XOY and with border $\mathrm{C}$. As shown in figure 4 the body is fixed in space by reducing the plane problem, and there are acting forces.

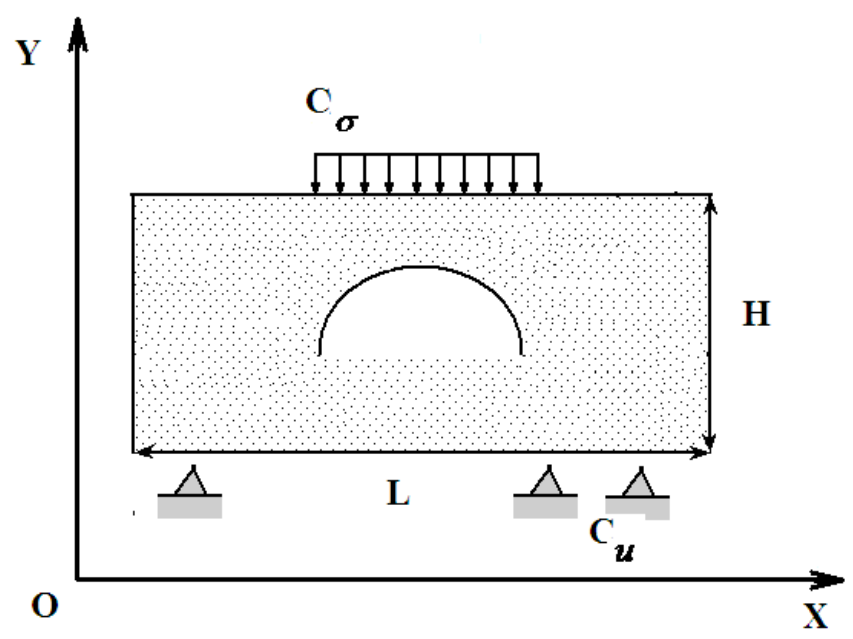

Fig. 4. The body under the actions

Suppose that under the action of these forces, deformations are small and for them equitable the following basic equations [6]:

1. Equations of equilibrium (static equation) 


$$
\begin{gathered}
\frac{\partial \sigma_{x}}{\partial x}+\frac{\partial \tau_{x y}}{\partial y}+\bar{X}=0, \frac{\partial \tau_{y x}}{\partial x}+\frac{\partial \sigma_{y}}{\partial y}+\bar{Y}=0 \\
\tau_{x y}=\tau_{y x}=\tau
\end{gathered}
$$

where $X$ and $Y$ are body forces. Or in matrix form

where $A=\left[\begin{array}{lll}\frac{\partial}{\partial x} & 0 & \frac{\partial}{\partial y} \\ 0 & \frac{\partial}{\partial y} & \frac{\partial}{\partial x}\end{array}\right], \quad \vec{\sigma}=\left[\begin{array}{ll}\sigma_{x} \sigma_{y} \tau\end{array}\right], \vec{P}=\left[\begin{array}{ll}\bar{X} & \bar{Y}\end{array}\right]$

2. Relationship between strains and displacements (geometric equation)

$$
\varepsilon_{x}=\frac{\partial u}{\partial x}, \quad \varepsilon_{y}=\frac{\partial v}{\partial y}, \quad \gamma_{x y}=\frac{\partial v}{\partial x}+\frac{\partial u}{\partial y},
$$

or

$$
\vec{\varepsilon}=A^{T} \vec{U}, \text { where } \vec{\varepsilon}=\left[\begin{array}{ll}
\varepsilon_{x} & \varepsilon_{y}
\end{array}\right]^{T}, \quad \vec{U}=\left[\begin{array}{ll}
u & v
\end{array}\right]^{T}
$$

3. Physical equations (Hooke's law)

$$
\varepsilon_{x}=\frac{1}{E}\left(\sigma_{x}-v \sigma_{y}\right), \quad \varepsilon_{y}=\frac{1}{E}\left(\sigma_{y}-v \sigma_{x}\right), \quad \gamma_{x y}=\frac{\tau_{x y}}{G}
$$

or

$$
\vec{\varepsilon}=B \vec{\sigma}
$$

$$
\text { where } \begin{aligned}
A= & {\left[\begin{array}{lll}
\frac{\partial}{\partial x} & 0 & \frac{\partial}{\partial y} \\
0 & \frac{\partial}{\partial y} & \frac{\partial}{\partial x}
\end{array}\right], \quad \vec{\sigma}=\left[\sigma_{x} \sigma_{y} \tau_{x y}\right], \vec{P}=\left[\begin{array}{ll}
\bar{X} & \bar{Y}
\end{array}\right] } \\
B & =\frac{1}{E}\left[\begin{array}{ccc}
1 & -v & 0 \\
-v & 1 & 0 \\
0 & 0 & 2(1+v)
\end{array}\right]
\end{aligned}
$$
[7]:

Then the equations of the theory of elasticity with boundary conditions can be written

$$
\begin{gathered}
\vec{\varepsilon}=A^{T} \vec{U}+\vec{P}=0 \\
\vec{\varepsilon}=B \vec{\sigma}
\end{gathered}
$$

Kinematic boundary conditions on the contour $C_{u}$

$$
\vec{U}=\vec{U}_{u}
$$

Static boundary conditions on the contour $C_{\sigma}$ 


$$
A_{c} \vec{\sigma}=\vec{P}_{\sigma}
$$

Here $\vec{U}_{u}, \vec{P}_{\sigma}$ - is displacement vector on the contour $-C_{u}$ and vector of a predetermined force on $-C_{\sigma}, A_{c}$ is matrix of direction cosines.

Let us express $\vec{\sigma}$ by second and third equations of the system (4):

Then

$$
\vec{\sigma}=B^{-1} A^{T} \vec{U}
$$

$$
B^{-1}=D=\frac{E}{1-v^{2}}\left[\begin{array}{ccc}
1 & v & 0 \\
v & 1 & 0 \\
0 & 0 & (1-v) / 2
\end{array}\right]
$$

For plane strain, Poisson's ratio $v$ is replaced by $\frac{v}{1-v}$.

Substituting the value of $\vec{\sigma}$ in the first equation (4) we obtain the following differential equation of the theory of elasticity in displacements in the matrix form:

$$
\begin{aligned}
A D A^{T} \vec{U}+\vec{P}=0 & \nabla=\varepsilon_{x}+\varepsilon_{y}=\frac{\partial u}{\partial x}+\frac{\partial v}{\partial y} \\
\text { or } \quad(\lambda+\mu) \frac{\partial \Delta}{\partial x}+\mu \nabla^{2} u+P_{x}=0 & , \quad \nabla^{2}=\frac{\partial^{2}}{\partial x^{2}}+\frac{\partial^{2}}{\partial y^{2}}, \lambda=\frac{v E}{(1-2 v)(1+v)} \\
(\lambda+\mu) \frac{\partial \Delta}{\partial y}+\mu \nabla^{2} v+P_{y}=0 & \mu=\frac{E}{2(1+v)}-\text { Lame constants }
\end{aligned}
$$

Now, for the formulation of the variational problem, we used differential equation (8) and the corresponding boundary conditions (5-6). Then, based on the Lagrangian variational principle $[8,9]$, the total potential energy functional $I$ must take a minimum value. Let's consider that the displacement vector of function $U(x, y)=[u(x, y), v\{x, y)]$ is minimized the function of the total energy of the system when the loaded condition in the form:

$$
I=\Pi+\bar{A}=\iint_{\Omega} F\left(u, v, \frac{\partial u}{\partial x}, \frac{\partial u}{\partial y}, \frac{\partial v}{\partial x}, \frac{\partial v}{\partial y}\right) d x d y
$$

under the constraint $\left.\vec{U}\right|_{C_{u}}=\vec{U}_{u}(x, y)$

Here $\left.\bar{A}=\iint_{\Omega} P_{x} u+P_{y} v\right) d x d y, \quad \Pi=\frac{1}{2} \iint_{\Omega}\left(\sigma_{x} \varepsilon_{x}+\sigma_{y} \varepsilon_{y}+\tau_{x y} \gamma_{x y}\right) d x d y$,

$\bar{A}$ is potential energy of external forces, $\Pi$ is potential energy of internal forces. Stationarity condition of functional equation (9), together with given boundary conditions, 
should be equivalent to a direct statement of the problem. Then, based on $[10,11]$, for quadratic functional $F$ to a two-dimensional problem can be written as follow

$$
F=\mu\left(\left(\frac{\partial u}{\partial x}\right)^{2}+\left(\frac{\partial v}{\partial y}\right)^{2}\right)+\frac{\lambda}{2}\left(\frac{\partial u}{\partial x}+\frac{\partial v}{\partial y}\right)^{2}+P_{x} u+P_{y} v
$$

From unimodality of problem of finding the minimum of functional we substitute equation (10) into the equation Euler (11):

$$
\begin{aligned}
& \frac{\partial F}{\partial u}-\frac{\partial}{\partial x} \frac{\partial F}{\partial u_{x}}-\frac{\partial}{\partial y} \frac{\partial F}{\partial u_{y}}=0 \\
& \frac{\partial F}{\partial v}-\frac{\partial}{\partial x} \frac{\partial F}{\partial v_{x}}-\frac{\partial}{\partial y} \frac{\partial F}{\partial v_{y}}=0
\end{aligned}
$$

On the basis of [12-14] can be obtained direct formulation of the problem.

Compliance with such equivalence (variational and direct statement of the problem) enables the use of the variational approach for solving the finite element method. To obtain discrete pattern in the area $\Omega$, are introduced the system of piecewise continuous basis functions $\left\{N_{m}(x, y)\right\}$ and nodal displacements $\vec{Z}_{m}[15,16]$. These basis functions are chosen automatically to satisfy kinematic boundary conditions of problem at the border $C_{u}$ :

$$
\begin{gathered}
\vec{U}=\sum_{m=1}^{M} N_{m}(x, y) \cdot \vec{Z}_{m} \text { or in matrix form } \vec{U}=N \vec{Z} \\
N=\left[\begin{array}{crrr}
N_{1} & 0 & N_{2} \ldots \ldots \ldots \ldots \ldots \ldots \ldots . .0 & N_{m} \\
0 & N_{1} & 0 \ldots \ldots \ldots \ldots \ldots \ldots \ldots N_{m} & 0
\end{array}\right], \vec{Z}=\left[Z_{1} \ldots \ldots \ldots Z_{m}\right]
\end{gathered}
$$

where $m=1 \ldots M$ is the number of nodes and basic functions. Then [15] satisfying kinematic boundary conditions, turning the system into the geometric unalterable system, we obtain the following system of equations in matrix form:

$$
K \vec{Z}=\vec{P}
$$

In solving the strength problems by finite element method is adopted the following procedure for the analysis of [17-19]:

1) construction of a model with the partition of the structure to a finite number of elements.

2) calculation of stiffness matrix and load vector elements by formula (12).

3) construction of complete stiffness matrix and full load vector.

4) solving the system of equations of the first degree according to a displacement of nodal point.

5) calculation of stresses and strains in the element according to formulas (5) and (6). 
The methodology of calculation of arch corrugated structure is modelled by beam and plane elements.

\section{Results and Discussion}

Consider the solution to the following task where the span of the reinforced concrete corrugated structure of vault is $20.6270 \mathrm{~m}$ and lifting boom in the key is $7.5703 \mathrm{~m}$. The structure is covered with backfill soil $0,75 \mathrm{~m}$ high from its surface with a bulk density $\gamma=19$ $\mathrm{kN} / \mathrm{m}^{3}$ weight $\gamma=24 \mathrm{kN} / \mathrm{m}^{3}$. The vault is made of concrete with strength class B35 [20]. The figure 5 shows cross-section of vault, which is reinforced with non-tensioned longitudinal reinforcement with diameter of $20 \mathrm{~mm}$ and $25 \mathrm{~mm}$ made by steel class A-III.
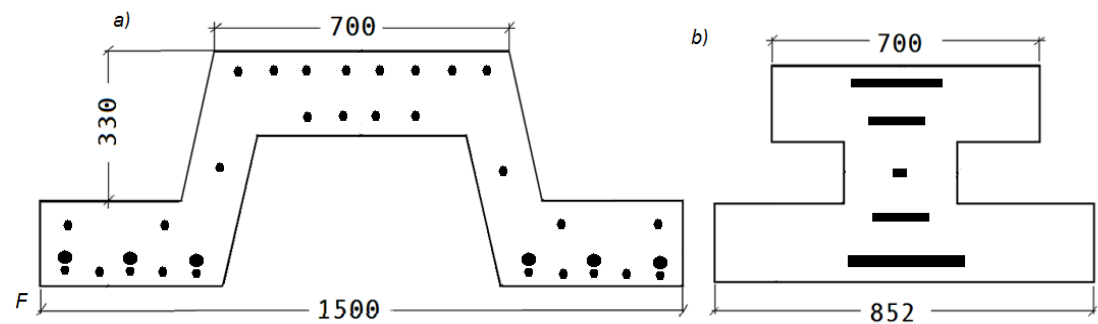

Fig. 5. Scheme of cross-section of vaulted structure (mm): 1) existing section, 2) reduced section

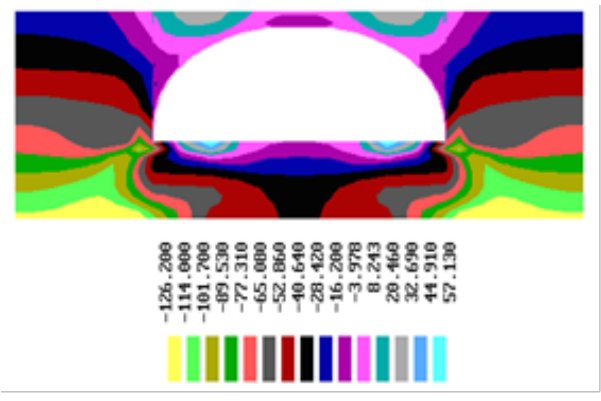

a)

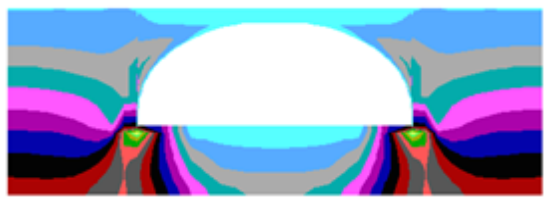

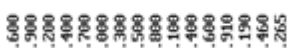

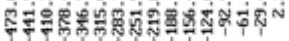
|||||||||||||

Fig. 6. Distribution of principal stresses (MPa): a) maximum, b) minimum

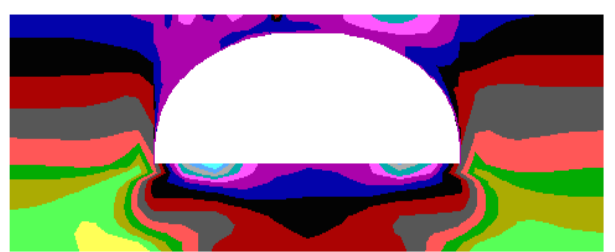

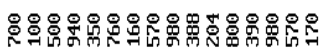

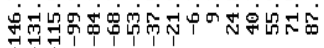
|||||||||||||

a)

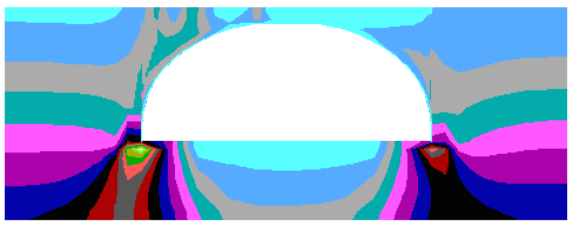

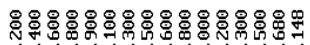

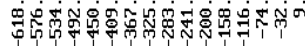
||||||||||||

b)

Fig. 7. Distribution of principal stresses (MPa): a) maximum, b) minimum 


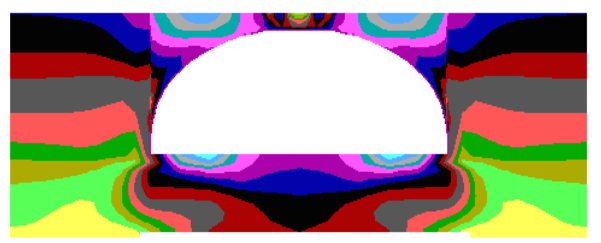

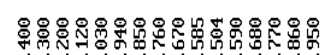

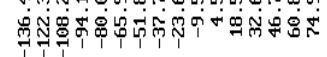

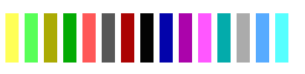

a)

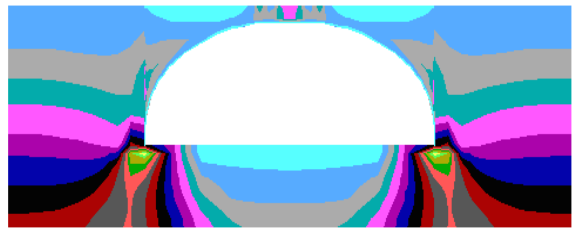

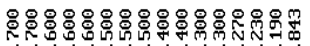

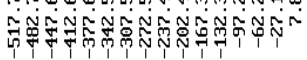
||||||||||||||

b)

Fig. 8. Distribution of principal stresses (MPa): a) maximum, b) minimum

At the first stage, we calculate the dead weight of the arch, road surface weight, and surrounding soil. Then various options of the location of temporary land transport load are considered: in middle of half-span and span of the arch.

Figures 6, 7 and 8 show calculation results in the form of maximum and minimum principal stresses. Also, stress distributions on the arch surface for three loading cases are shown in figure 9. Analyzes show that the third option is considered as most loaded, that is, when a vehicle of transport load is in the middle of the bridge. In this case, the arched structure obtains maximum internal forces in its sections.

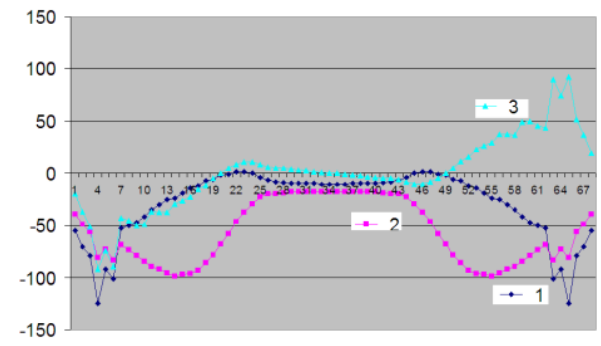

a)

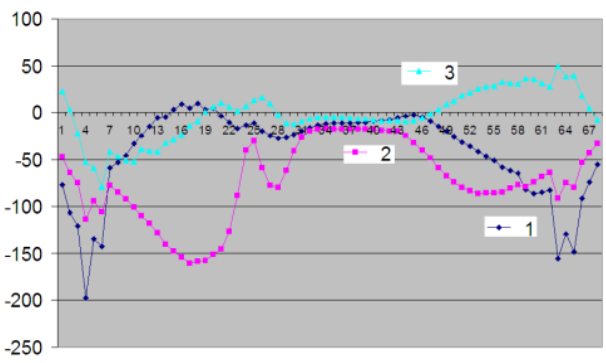

b)

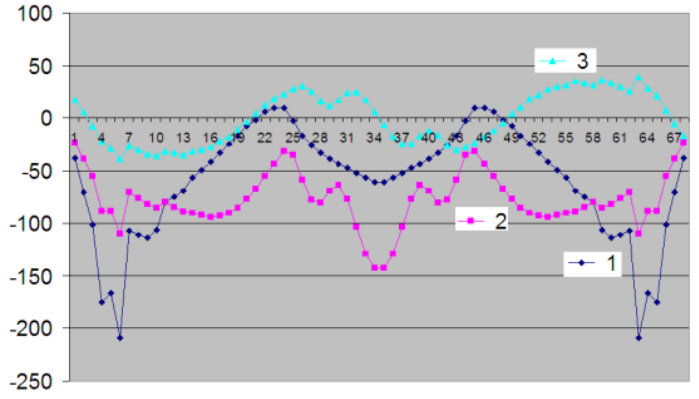

c)

Fig. 9. Stress distribution (MPa): a) without land transport load, b) land transport load is in the middle of semi-arch, c) land transport load is in the middle of arch: 1 is horizontal stress, 2 is vertical stress, 3 is shear stress 


\section{Conclusions}

At the present time in transport construction, a perspective direction is to use low-span arched backfill road bridges, which allow replacing culverts and low-span beam bridges. Lightweight prefabricated structures allow using light lifting capacity cranes without using special lifting and transport equipment

The model and calculation method for the objective assessment of stress-strain state parameters of corrugated structure of arched backfill road bridge exposed to modern land transport load is developed. In the course of numerical studies, normal stresses were determined in sections of reinforced concrete corrugated structure as well as in the surrounding soil. The calculation results are presented in the form of stress isochromes and diagram.

\section{References}

1. G. E. Tan, T. B. Ong, K. K. Choong, C. Y. Ong IOP Conf. Ser. (2013)

2. M. K. Miralimov Appl. Mech. Mater. 2015

3. G. E. Tan, T. B. Ong, C. Y. Ong Applied mechanics and materials (2015)

4. H. F. Wang, M. L. Lou, and R. L. Zhang Soil dyn. Earthq. Eng. (2017)

5. H. F. Wang, M. L. Lou, X. Chen, and Y. Meizhai Soil Dyn. Earthq. Eng. (2013)

6. R. A. Abirov J. Mech. Behav. Mater. 18, 341 (2007)

7. M. K. Usarov Mag. Civ. Eng. 53, 802015

8. M. M. Mirsaidov and E. S. Toshmatov Mag. Civ. Eng. (2019)

9. C. Y. Ong, K. K. Choong, and M. Miralimov In Aip Conf. Proc. (2017)

10. A. Abirov In Proc. 6th Int. Disaster Risk Conf. Integr. Risk Manag. - Towar. Resilient Cities, IDRC Davos 2016

11. M. M. Mirsaidov and T.Z. Sultanov and A. Sadullaev Mag. Civ. Eng. (2013)

12. M. Usarov, G. Mamatisaev, J. Yarashov and E. Toshmatov In J. Phys. Conf. Ser. (2020)

13. P. P. Oreste Undergr. Sp. Technol. (2007)

14. M. M. Miralimov Eur. J. Tech. Nat. Sci. (2019)

15. M. M. Mirsaidov and T.Z. Sultanov Mag. Civ. Eng. (2014)

16. C. Y. Ong, J. B. Yeo, K. K. Choong, and M. Miralimov Int. J. Struct. Civ. Eng. Res. (2015)

17. M. Miralimov In Iop Conf. Ser. Mater. Sci. Eng. 2019

18. M. S. B. Zainordin, N. A. B. Yusoff, T. N. J. Tuanchik, M. B. Manap, Z. Sayuti, M.F.

B. Abdullah Applied Mechanics and Materials (2015)

19. C. Y. Ong, J. B. Yeo, K. K. Choong and M. Miralimov Int. J. of Struct. and civil eng. res. (2015)

20. R. Abirov, M. Miralimov, Planet@Risk, 2, 3, (2015) 